Ensino, Saúde e Ambiente - V 7 (1), Edição Especial, maio de 2014

\title{
VISÕES SOBRE A TEORIA EVOLUTIVA: PRESSÕES INSTITUCIONAIS RELIGIOSAS E CIÊNCIA.
}

\section{VIEWS ON EVOLUTION THEORY: INSTITUCINAIS RELIGIOUS PRESSURE AND SCIENCE.}

\author{
Viviane Vieira ${ }^{1}$, Eliane Brígida Morais Falcão ${ }^{2}$ \\ ${ }^{1}$ Universidade Federal do Rio de Janeiro /Núcleo de Tecnologia Educacional Para a Saúde, \\ vivianevieira.biologia@gmail.com \\ ${ }^{2}$ Universidade Federal do Rio de Janeiro /Núcleo de Tecnologia Educacional para a Saúde /Observatório \\ da Laicidade da Educação, elianebrigida@uol.com.br
}

\section{RESUMO}

Investigou-se a representação da teoria evolutiva de uma docente de um colégio religioso, cujo projeto pedagógico associava explicações bíblicas aos conteúdos científicos das disciplinas regulares. Para isso, foram investigados seus pensamentos, visões e atitudes frente à teoria evolutiva em sala de aula, em entrevista e visita à UFRJ. O referencial teórico metodológico foi a teoria das representações sociais. Os resultados mostraram que, nos espaços escolares, a docente mostrava restrições às explicações científicas no confronto com preceitos bíblicos e, no ambiente universitário, revelava adesão à abordagem científica. Concluiu-se que a sua prática docente era limitada pelo vinculo institucional e compromisso com o projeto escolar religioso. $\mathrm{Na}$ universidade, ela encontrava reconhecimento e liberdade para expressar seu interesse pela ciência, no caso, teoria da evolução. A necessidade da laicidade no ensino de ciências precisa de reflexão nos meios educacionais para que o acesso correto aos conteúdos científicos seja garantido a todos os estudantes.

Palavras-chave: ensino de ciências; teoria da evolução; representações sociais; ensino médio; laicidade.

\begin{abstract}
We investigated the representation of evolutionary theory from a instructor of a religious school, whose pedagogical project associated biblical explanations in scientific content of regular courses. For this, we investigated her thoughts, views and attitudes of evolutionary theory in the classroom, in an interview and visit to the UFRJ. The theoretical framework was the social representations theory. The results showed that, in school spaces, the instructor showed restrictions on scientific explanations in confrontation with biblical precepts and, in university, she showed adherence to the scientific approach. It was concluded that the instructor's teaching practice was limited by institutional bond and commitment to the religious school project. At university, she found recognition and freedom to express her interest in science, in case of evolution's theory. The demand of secularism science teaching needs a reflexion in educational contexts to ensure the correct scientific content access to all students.
\end{abstract}

Key words: science education; theory of evolution; social representations; secondary education and secularism. 2014. 


\section{INTRODUÇÃO E OBJETIVOS.}

A teoria evolutiva ${ }^{1}$ consiste em um conjunto de explicações cientificamente plausíveis para a origem das espécies, inclusive da espécie humana. Apesar dos conceitos dessa teoria ser, em sua maioria, um consenso para a comunidade científica, os resultados de algumas pesquisas no ensino de ciências mostram diferentes configurações das dificuldades relacionadas ao seu ensino. A este trabalho interessa investigar as dificuldades relacionadas às interferências das crenças religiosas no ensino da evolução das espécies.

Algumas pesquisas (ALEXAKOS \& PIERWOLA, 2013; ALMEIDA, 2012; BOUJAOUDE ET AL, 2011; COSTA, MELO \& TEIXEIRA, 2011; FALCÃO, SANTOS \& RAGGIO, 2008; GRIMES \& SCHROEDER, 2013; OLEQUES, SANTOS \& BOER, 2011; OLIVEIRA \& BIZZO, 2011 e PORTO \& FALCÃO, 2010) mostraram que crenças religiosas de professores e estudantes interferiam na aceitação de conceitos específicos da teoria evolutiva como adaptação, ancestralidade comum, evolução humana e seleção natural. Resultados destas pesquisas revelaram que o criacionismo era expresso ou ensinado alternativamente à teoria evolutiva.

A presente pesquisa é parte de um projeto em andamento sobre as representações sociais expressas no contexto do ensino médio de uma escola adventista do estado do Rio de Janeiro sobre ciências (VIEIRA \& FALCÃO, 2012a) e evolução das espécies (VIEIRA \& FALCÃO, 2012b), em que foi possível associar a ampla adesão dos estudantes ao discurso criacionista com o Projeto Político Pedagógico da escola, que estabelecia princípios bíblicos cristãos como norteadores do ensino oferecido. Os resultados destas investigações mostraram que o projeto escolar estabelecia o compromisso dos professores com tais princípios. A presente pesquisa buscou investigar pensamento e atitudes da docente de Biologia deste colégio responsável pelo ensino da teoria evolutiva - em relação a tal projeto e à teoria da evolução. Buscou-se compreender como ela lidaria com seus objetivos profissionais de ensinar a teoria evolutiva em uma escola que, simultaneamente, estabelecia as

\footnotetext{
${ }^{1}$ Teoria da evolução ou teoria evolutiva ou evolução biológica ou evolução das espécies ou evolução, nesta pesquisa, são termos intercambiáveis.

Edição Especial com os melhores trabalhos apresentados no IV ENECiências: UFF - 13 a 16 de maio de 2014.
} 
explicações bíblicas para a origem das espécies e a oferta do ensino dos conteúdos científicos exigidos nos Parâmetros Curriculares Nacionais para o Ensino Médio (PCNEM). A escola pretendia que os estudantes fossem aprovados nos exames de vestibulares de universidades, em especial de instituições públicas.

\section{REFERENCIAL TEÓRICO, CONTEXTO DE PESQUISA E PROCEDIMEN TOS METODOLÓGICOS.}

Considerando o contexto de ensino condicionado pelo Projeto Político Pedagógico, buscou- se identificar as concepções, visões e valores da docente sobre a teoria evolutiva, utilizando-se o conceito de representação social. Este conceito estabelece as bases não só para a identificação do imaginário do sujeito pesquisado como articulações com o mundo social, aí incluídos os processos educativos.

De acordo com Moscovici (2003), as representações sociais devem ser vistas como uma "atmosfera" em relação ao indivíduo ou ao grupo (op. cit., p.53) e como uma maneira específica de um grupo para compreender e comunicar o que sabe. Trata-se do universo consensual, onde a sociedade possui uma voz humana (id., p.49). Portanto, as representações sociais são construções sociais de um indivíduo ou determinado grupo que compartilha sistema de crenças, valores e ações em um contexto social típico - a respeito de um tema. Na construção das representações sociais, dois processos são fundamentais: a ancoragem e a objetivação. $\mathrm{Na}$ ancoragem, coisas estranhas a um determinado grupo são nomeadas e classificadas. É a partir da ancoragem, que ideias são transformadas em categorias e imagens comuns. Enquanto que na objetivação, algo abstrato é transformado em algo quase concreto, portanto, associa-se algo que está na mente com algo que exista no mundo.

Utilizando este referencial, foram estabelecidos os objetivos e o roteiro metodológico da pesquisa aqui relatada: investigar a representação social da docente em relação ao tema evolução das espécies e analisá-la à luz de sua atividade docente.

A infraestrutura do colégio contava com recursos didáticos pedagógicos modernos, uma sala de informática, salas de aula com quadros brancos, carteiras confortáveis para os estudantes e ar-condicionado, quadras de esportes cobertas, lanchonetes, auditórios para reuniões com os responsáveis, apoio de um psicólogo e 2014. 
uma coordenadora pedagógica. No entanto, a escola não possuía um laboratório de ciências e ainda continha uma livraria especializada em produtos religiosos (bíblias, CD’S de músicas evangélicas, camisas com mensagens religiosas, etc.). Além disso, é importante mencionar que a escola fazia parte da estrutura de uma Igreja Adventista e não apresentava temas científicos em seus murais, panfletos ou cartazes. Estes espaços eram ocupados completamente por conteúdos bíblicos.

No projeto escolar, o professor recebia orientação para que articulasse os conteúdos das disciplinas regulares (Português, Matemática, Biologia, etc.) com os princípios bíblicos cristãos, ou seja, cada conteúdo destas disciplinas devia estar associado com a palavra bíblica. Igualmente, era orientado para incluir valores cristãos na metodologia de ensino. Um trecho do projeto escolar exemplifica este enunciado:

"O que o professor ensina deve estar baseado nos Princípios Bíblicos que
são imutáveis, para que os absolutos de Deus permeiem todo o conhecimento
acadêmico em cada disciplina (Português, Matemática, Ciências, História,
etc.)".

É importante dizer: ainda que associe os princípios bíblicos às matérias regulares, a escola possuía um bom rendimento no Exame Nacional do Ensino Médio (ENEM) quando comparado ao conjunto das escolas do Brasil. A posição nacional dessa escola no Ranking do ENEM (ENEM, 2012²) aproximava-se do $4000^{\circ}$ lugar, no universo de 11.239 escolas analisadas. Outro aspecto importante é o fato dos estudantes visitarem centros de pesquisas como UFRJ e Fiocruz e exposições em museus de ciências ao menos uma vez ao ano.

A grade curricular do ensino médio deste colégio era constituída, além das disciplinas regulares (Português, Matemática, Biologia, Física, Química, História, Geográfica, Literatura, Inglês, Espanhol e Redação), do Estudo Bíblico, de caráter obrigatório, ocupando 1 hora por semana desta grade.

A docente pesquisada, licenciada em Ciências Biológicas, lecionava 3 horas de Biologia por semana em cada turma do ensino médio, ou seja, trabalhava, no mínimo, 9

\footnotetext{
2 Foram incluídas nesta análise somente aquelas escolas em que mais de 10 estudantes fizeram a prova, com mínimo de $50 \%$ dos estudantes matriculados no $3^{\circ}$ ano do ensino médio em escolas públicas e privadas do Brasil.
}

Edição Especial com os melhores trabalhos apresentados no IV ENECiências: UFF - 13 a 16 de maio de 2014. 


\section{Ensino, Saúde e Ambiente - V 7 (1), Edição Especial, maio de 2014}

horas por semana no seu contexto de ensino. Estava vinculada à escola, como docente, há 2 anos e complementava o salário como revendedora de cosméticos. Demonstrou interesse em desenvolvimento profissional, à época dos contatos e atividades de pesquisa: realizava um curso lato sensu em Análises Clínicas numa universidade da rede privada de ensino. E, ao longo da pesquisa aqui relatada, mostrou interesse, quando visitou os laboratórios e o Museu da Geodiversidade da UFRJ, de fazer pós-graduação na própria área da Biologia ou no Ensino de Ciências.

Os procedimentos metodológicos desta pesquisa incluem três etapas: 1 Observação da atuação da docente nas três aulas sobre a teoria evolutiva no colégio; 2. Observação de seu comportamento durante uma visita ao Museu da Geodiversidade e laboratórios de pesquisa científica da UFRJ, onde pretendia- se investigar a repercussão de uma imersão num contexto de produção de conhecimento científico nos estudantes e na docente e 3. Entrevista semiestruturada com perguntas relacionadas à teoria da evolução.

A docente foi esclarecida da participação não obrigatória na pesquisa, do seu anonimato, dos objetivos do estudo, de que não haveria prejuízos, bem como nenhum ônus, garantia, ou quaisquer benefícios adicionais em relação ao seu contexto profissional. Foi, portanto, criado um clima agradável e confiável entre a pesquisadora e a docente.

$\mathrm{O}$ roteiro das perguntas da entrevista foi baseado tanto no contexto religioso escolar como na observação das aulas da docente, onde as explicações religiosas eram articuladas às explicações científicas e envolveu os seguintes temas relativos à evolução das espécies: 1. Criacionismo; 2. Teoria da evolução e 3. Evolução humana. Com este roteiro, pretendeu-se buscar o pensamento mais espontâneo da docente afastando-a do contexto de avaliação de conhecimento sobre o tema. Além disso, a formulação destas perguntas manteve os termos usados por ela e pelos estudantes em aulas observadas: por exemplo, a expressões "crença" ou "eu acredito" ou "não acredito" quase sempre eram associadas tanto à "crença" na teoria da evolução como à "crença" na intervenção divina na origem da espécie humana. 2014. 
Esta pesquisa foi aprovada pelo Comitê de Ética em Pesquisa da Escola de Enfermagem da UFRJ (protocolo de aprovação: 00653512.8.0000.5257). Foi permitida a observação de aulas e de outras dependências da escola tanto pela direção, como pela docente, que aceitou, com interesse, ser observada e entrevistada.

\section{RESULTADOS E DISCUSSÃO.}

OBSERVAÇÃO DA DOCENTE EM SALA DE AULA.

Nas três aulas de ensino da teoria evolutiva, observou-se que a docente tanto ensinava conceitos científicos do tema (mutação, adaptação, seleção natural e variabilidade gênica) como lembrava explicações bíblicas. Confira-se o exemplo de uma das aulas:

"as espécies mudam seu código genético e sofrem adaptações e evoluções";

"Deus criou essa tamanha diversidade. Olha gente, como Deus é bom!"; "O mecanismo seleção natural provoca resistência das bactérias à antibióticos, adaptando elas ao meio". "Deus não criou o ovo, Deus criou a espécie já formada".

Em outra atividade, seminário intitulado "criacionismo x evolucionismo", um estudante afirmou que a ciência defendia a evolução das espécies ao longo do tempo e que, de acordo com a teoria da evolução, o homem tinha vindo do macaco. Para ele e seu grupo,

"isso contradiz a afirmação bíblica que o homem tinha sido feito à imagem e semelhança de Deus e, por isso, esta evolução não poderia ser verdade, porque contraria o preceito da criação das espécies realizada por Deus".

Diante de tais afirmações, a docente acenava positivamente para os estudantes, aprovando aquelas considerações e não emitia qualquer comentário para corrigir ou discutir as asserções do estudante. O seminário transcorreu com as explicações científicas da teoria (mutação, seleção natural e variabilidade gênica), mas também com críticas à evolução humana com base em explicações bíblicas, conforme apresentadas por outro grupo de estudantes no referido seminário:

"Deus criou o homem à sua imagem e semelhança, então não sofreu uma evolução"; "O homem veio do barro, a ciência diz também que existem moléculas geradores de vida nas cinzas".

A observação das três aulas permite afirmar que as explicações da teoria evolutiva eram expressas num contexto de ensino de desvalorização da explicação científica frente à explicação criacionista, considerada a única explicação correta. Os 2014. 
pontos mais conflitantes referiam-se à origem das espécies (em contraposição à origem de seres "já adultos" ou "formados", coerentes com o texto bíblico) e à aceitação da descendência do ser humano "diretamente do macaco", que contraporia à crença na origem divina da espécie humana. O esclarecimento correto sobre ancestralidade comum entre a espécie humana e os macacos (a espécie humana possui um ancestral comum com os macacos e este ancestral originou tanto espécies de macacos como espécies de hominídeos) não foi apresentado aos estudantes. Havia uma preocupação constante da docente em deixar clara a primazia da religião em relação à ciência quando ela intercalava afirmações científicas com ressalvas religiosas.

\section{OBSERVAÇÃO DA DOCENTE NA UNIVERSIDADE.}

$\mathrm{Na}$ visita (9hs às 18hs.) aos laboratórios de pesquisa (Laboratório de Genética, Laboratório de Paleontologia e Laboratório de Anatomia) e ao Museu da Geodiversidade da UFRJ, aonde o tema evolução humana também foi abordado, a docente, constantemente, mostrou interesse nos conteúdos expostos pelos pesquisadores dos laboratórios e monitores do Museu: levantou questionamentos científicos e estimulou os estudantes a interagirem com os monitores e os temas abordados, chamando atenção para os fósseis, semelhanças anatômicas entre as espécies observadas e equipamentos utilizados nos laboratórios. Quando o tema evolução humana foi abordado, foram apresentadas as evidencias evolutivas como semelhanças entre os crânios de hominídeos e crânios de chimpanzés, inclusive, nos laboratórios, houve comparação e manipulação de diferentes órgãos humanos e de outras espécies. Nesse contexto, a docente envolveu-se nas atividades sem expressar qualquer constrangimento com a fala dos monitores e pesquisadores ao exporem explicações científicas da evolução. Em conversas, ao longo da visita, ela declarou interesse por cursos de pósgraduação em Biologia e Ensino de Ciências da universidade, e não manifestou qualquer posicionamento religioso.

As diferenças no comportamento da docente, nos dois ambientes de características completamente distintas, o colégio confessional e a universidade laica, foram notórias. O colégio, ambiente institucional de trabalho desta docente, era condicionado pelo projeto pedagógico articulado às crenças religiosas, que exigia 2014. 
desempenho específico de seus professores. O contrato de trabalho de seus funcionários era mantido com respeito a tal exigência. Na universidade, onde eram oferecidos cursos de graduação e de pós - graduação, a docente encontrou espaço para expressar livre interesse pela ciência e, consequentemente, refletir sobre os fenômenos naturais de origem e evolução das espécies sem os limites impostos pelo projeto escolar religioso.

Um momento da entrevista (relatada no próximo tópico) comprova este enunciado e o interesse e a motivação da docente pelas explicações científicas abordadas na visita ao Museu da Geodiversidade:

"Ele (o monitor do museu) foi falando coisas (...) que me acrescentaram muito (...), porque eu até havia observado quando tinha trabalhos (...) na escola, os alunos, que sempre traziam fósseis, (...), falavam como se esses homens vivessem em épocas diferentes. Mas na verdade, até o monitor disse: não, eles (hominídeos) até viviam no mesmo tempo, porém em lugares diferentes. (...) Foi bacana, me acrescentou essa ida ao Fundão... em relação a isso. Eu gostei (...) bastante”.

\section{A ENTREVISTA COM A DOCENTE.}

A entrevista foi realizada na sala dos professores, mobiliada por uma mesa, um computador, cadeiras para reuniões e estantes. Nessas, havia bíblias expostas com livros de disciplinas regulares da escola. No momento da entrevista, somente estavam presentes a entrevistadora e a docente. A entrevista investigou, conforme explicado na metodologia, os seguintes temas: 1. Criacionismo; 2. Teoria da evolução e 3. Evolução humana.

\section{TEMÁTICA CRIACIONISMO.}

Ao ser solicitada que falasse sobre o criacionismo, a docente afirmou:

“(...) o criacionismo não é ciência, o criacionismo é bíblico, ele não tem nada a ver com a ciência, até porque pra se escrever uma hipótese foi feito o método cientifico. (...) Minha crença não interfere no ensino da teoria da evolução: eu sigo as orientações do projeto escolar. Até porque quem matricula o filho numa escola cristã, sabe que nós temos uma base, uma linha, né? Totalmente cristã de pensamento".

A docente foi clara e direta: "o criacionismo não é ciência, (...) é bíblico" e, o ensina, porque segue as "orientações do projeto escolar”. E ressalta: "minha crença não interfere no ensino da teoria da evolução". O projeto escolar orientava o ensino religioso articulado aos conteúdos das disciplinas da escola:

"O que o professor ensina deve estar baseado nos Princípios Bíblicos (...),
para que os absolutos de Deus permeiem todo o conhecimento acadêmico em Edição Especial com os melhores trabalhos apresentados no IV ENECiências: UFF - 13 a 16 de maio de 2014. 
Ensino, Saúde e Ambiente - V 7 (1), Edição Especial, maio de 2014

cada disciplina (Português, Matemática, Ciências, História, etc.)”. (Projeto da Escola)

\section{TEMÁTICA TEORIA DA EVOLUÇÃO.}

Foi perguntado: você acredita na teoria da evolução? A docente respondeu:

“(...) a teoria da evolução afirma que o primeiro ser vivo foi uma célula, enquanto a bíblia afirma que o primeiro ser vivo foi um organismo já na sua forma adulta. (...) A bíblia me diz que Deus não criou célula. Deus não criou ovo. Deus criou criatura (...) A teoria evolucionista vai me dizer que foi o ovo. A teoria criacionista me diz que foi a galinha, porque Deus criou a espécie (...).A origem do Universo, da Terra, da vida e das espécies não poderia acontecer sem que a mão de Deus ali não estivesse(...).Hipoteticamente, do jeito que ela é, pode-se aceitar a teoria da evolução. Agora se ela vier com peso de afirmações, aí já seria diferente. (...) Não há comprovações palpáveis para essa teoria".

A docente respondeu estabelecendo comparações entre a abordagem religiosa e científica da origem das espécies e afirmou ser correto ensinar o texto bíblico que afirma a criação das espécies por Deus. E ciência, aceita "hipoteticamente", poderia ser um caminho de lidar com a evolução. Pode - se perceber os esforços da docente para conciliar ciência e crença religiosa: considerar a teoria evolutiva como hipóteses não comprovadas.

\section{TEMÁTICA EVOLUÇÃO HUMANA.}

Diante da pergunta: você acredita na evolução humana? A docente respondeu:

"Eu não acredito. (...) Essa coisa que o homem evoluiu do macaco, falando da teoria evolutiva, isso daí é coerente (...). Mas isso não quer dizer que eu vou acreditar nisso. (...) Ensinar para os alunos, eu ensinaria, por quê?? Hoje quando eu falo de genética (...) e (...) evolução. (..), eu vejo que existem estruturas como hemácias humanas, hemácias de coelhos(...). Somos de espécies totalmente diferenciadas, porém temos estruturas assemelhadas. Parentesco (risos) evolutivo que nós temos. (...). Mas não quer dizer que somos da mesma espécie. É diferente dizer que tem um parentesco evolutivo. É como ser da mesma família e diferente (risos). (...)Pela teoria evolutiva isso é passado".

O depoimento da docente intercalava termos da teoria evolutiva, restrições com conotação religiosa e risos eventuais, que sugeriam autocrítica diante das próprias afirmações. Parecia ter consciência de sua ambivalência ou desconforto por expressar afirmações contraditórias relativas ao tema, que ela mesma, como bióloga, tinha conhecimento científico. Insistia na afirmação incorreta de que a espécie humana veio diretamente do macaco, mesmo conhecendo, por sua formação (e visita à UFRJ), a explicação correta deste tema, ancestralidade comum. Essa afirmação incorreta dava Edição Especial com os melhores trabalhos apresentados no IV ENECiências: UFF - 13 a 16 de maio de 2014. 
base para rejeitar a "hipótese" da ciência e afirmar a crença num Deus criador. No entanto, na visita à universidade (Museu da Geodiversidade e laboratórios), a sua postura foi a de compartilhamento da abordagem científica da diversidade das espécies. Sua interação com os monitores e pesquisadores estudiosos do tema foi espontânea e interessada.

A representação da docente em relação à teoria evolutiva mostrou contradições claramente associadas ao projeto do colégio. Em momentos específicos (sala de aula e entrevista), ela criticava aspectos da evolução que pareciam confrontar-se com princípios bíblicos. Em contexto fora da escola (Museu da Geodiversidade e laboratórios de pesquisa da UFRJ), a docente parecia aceitar e compreender a teoria da evolução, inclusive "ancestralidade comum”. Em suma, o seu vínculo ao colégio (contrato de trabalho) acarretava compromisso com o projeto religioso da escola, condicionante de sua visão da teoria evolutiva nos espaços do colégio. Quando distante deste contexto, num papel de visitante, a docente de Biologia mostrou espontaneidade e abertura às explicações científicas da teoria evolutiva. Sua formação de Bióloga pareceu compatível com o ambiente acadêmico.

Comparando-se os dados coletados nas situações investigadas (sala de aula, universidade e entrevista na escola) não se tem base para afirmar que a docente era religiosa e criacionista e, por isso, criticava a teoria da evolução. Antes, pareceu submetida às condições de trabalho que dela exigiam compromisso com o projeto escolar religioso. Nesse sentido, uma reflexão se faz necessária: a importância da laicidade no ensino de ciências. $\mathrm{O}$ respeito às crenças religiosas de todos é garantido constitucionalmente no Brasil, conforme atestam as Diretrizes Curriculares Nacionais para o Ensino Básico:

“(...) consolidar a instituição escolar como espaço democrático que reconhece e respeita a diversidade” (BRASIL, 2013, p.130).

Entretanto, a laicidade, prevista neste documento e nas Orientações Complementares aos Parâmetros Curriculares Nacionais, é restringida à escola pública:

\footnotetext{
"No caso das escolas públicas, deve-se assegurar o caráter laico do ensino,
} conforme determina a lei" (BRASIL, 2006, p.39). 2014. 
O acesso ao ensino de ciências é parte relevante da educação básica. Oferecer o ensino de ciências, onde não se distingue campos da ciência e da religião, submetendo um ao outro, ou seja, ciência à religião, descumpre um direito constitucional dos jovens estudantes.

\section{CONSIDERAÇÕES FINAIS.}

Esta pesquisa investigou atitudes e representação da teoria evolutiva de uma docente de um colégio, cujo projeto escolar associava princípios bíblicos ao ensino das disciplinas regulares. No contexto da escola, o vínculo profissional acarretava o compromisso docente com o projeto religioso institucional, o que limitava o ensino da teoria evolutiva: a docente apresentava a evolução num contexto de desvalorização das explicações científicas. No entanto, no contexto da universidade, ela compartilhava as explicações científicas da evolução expressando seu interesse pela ciência. Sem restrições ao direito de crenças religiosas, os resultados deste trabalho apontam para a necessidade do caráter laico no ensino de ciências para que seja garantido o ensino correto dos conteúdos científicos a todos os estudantes.

\section{REFERÊNCIAS}

1.ALEXAKOS \& PIERWOLA. Learning at the "boundaries": radical listening, creationism, and learning from the "other". Cult Stud of Sci Educ. v.8, p.39-49,2013.

2.ALMEIDA. Concepções de alunos do ensino médio sobre a origem das espécies. Ciência \& Educação. v. 18, n. 1, p. 143-154, 2012.

3.BOUJAOUDE ET AL. Muslim Egyptian and Lebanese Students' Conceptions of Biological Evolution. Sci \& Educ.vol. 20, p.895-915,2011.

4. BRASIL, MINISTÉRIO DA EDUCAÇÃO. Orientações Complementares aos Parâmetros Curriculares Nacionais (PCN+), 2006. Disponível em: www.portal. mec.gov.br. Acessado em 12/10/2012.

5.BRASIL.MINISTÉRIO DA EDUCAÇÃO. SECRETARIA DE EDUCAÇÃO. Diretrizes Curriculares Nacional Para a Educação Básica , 2013. 542p. Disponível em: portal.mec.gov.br/ index.php?option=com_docman\&task. Acessado em 05/02/2014.

6.COSTA, MELO \& TEIXEIRA. Reflexões acerca das diferentes visões de alunos do ensino médio sobre a origem da diversidade biológica. Ciência \& Educação, v. 17, n. 1, p. 115-128, 2011. 2014. 
7.FALCÃO, E. B. M.; SANTOS, A. G.; RAGGIO, R. Conhecendo o mundo social dos estudantes: encontrando a ciência e a religião. Revista Eletrónica de Enseñanza de lãs Ciencias, v. 7, n. 2 p. 420-438. 2008.

8.GRIMES \& SCHROEDER. A origem da vida, sob a ótica de licenciandos de um curso de Ciências Biológicas. Revista Electrónica de Enseñanza de las Ciencias.vol. 12, n. 1, 126-143, 2013.

9.MOSCOVICI, S. Representações sociais - Investigações em Psicologia Social. Petrópolis: editora: Vozes, 2003.

10. OLEQUES, SANTOS \& BOER. Evolução biológica: percepções de professores de Biologia. Revista Electrónica de Enseñanza de las Ciencias. vol 10, n. 2, 243-263, 2011.

11. OLIVEIRA \& BIZZO. Aceitação da evolução biológica: atitudes de estudantes do ensino médio de duas regiões brasileiras. Revista Brasileira de Pesquisa em

Educação em Ciências. vol. 11, n. 1, 2011.

12. PORTO, P. \& FALCÃO, E. B. M.Teorias da origem e evolução da vida: dilemas e desafio no ensino médio. Revista Ensaio, v. 12, n. 3 p. 13-30. 2010.

13. BRASIL ESCOLA. Ranking ENEM, 2012. Disponível em: http://vestibular.brasil escola.com/enem.Acessado em 15/01/2013.

14.VIEIRA,V \& FALCÃO, E. B. M. "Eu não confio na evolução, mas no resto eu confio quase que às cegas". Evolução biológica: o limite entre a ciência e a crença religiosa.

Revista Ensino, Saúde e Ambiente - v5. n.2, pp. 138-148, 2012 a.

15.VIEIRA, V \& FALCÃO, E. B. M. Laicidade e ensino de ciências: a necessária reflexão na escola privada. Revista Alexandria: revista em Educação em Ciência e Tecnologia. v5, n.3, pp. 83-100, 2012b. 